\title{
Effects of heat pump drying temperature and dietary fat on carrot $\beta$-carotene bioaccessibility
}

\author{
Sun Xiaofei ${ }^{1,2}$, Zhu Wenxue ${ }^{2 *}$, Li Xinling ${ }^{2}$, Fan J inling ${ }^{2}$ \\ (1. School of Food and Biological Engineering, Jiangsu University, Zhenjiang 212013, China; \\ 2. College of Food and Bioengineering, Henan University of Science and Technology, Luoyang 471023, China)
}

\begin{abstract}
Dehydration can significantly extend the shelf life of dried carrots and still retain nutrition of provitamin A carotenoids. In vitro digestion model was used in this study to assess the effect of drying temperatures of heat pump and dietary fat on the bioaccessibility of $\beta$-carotene in carrots. Also, low-speed centrifugation was employed to obtain $\beta$-carotene release rate in supernatant. Microfiltration was applied to obtain $\beta$-carotene micellar rate in micelle phase. These assays were used as indicators to assess the bioaccessibility of the $\beta$-carotene. Despite higher drying temperatures had a negative effect on the retention rate of $\beta$-carotene in carrots, it showed a positive impact on the micellar rate. In addition, dietary fat significantly increased the release rate and micellar rate of $\beta$-carotene for both fresh carrots and dried carrot products, with the highest release rate and micellar rate obtained when $10 \%$ dietary fat was added. Therefore, the heat pump drying process and dietary fat can significantly improve the bioaccessibility of $\beta$-carotene in carrots, which may increase the $\beta$-carotene bioavailability to human.
\end{abstract}

Keywords: bioaccessibility, in vitro digestion, $\beta$-carotene, carrot, heat pump drying

DOI: $10.25165 /$ j.ijabe.20171004.2375

Citation: Sun X F, Zhu W X, Li X L, Fan J L. Effects of heat pump drying temperature and dietary fat on carrot $\beta$-carotene bioaccessibility. Int J Agric \& Biol Eng, 2017; 10(4): 234-242.

\section{Introduction}

Carrots are rich in vitamins and minerals and contain a high content of carotenoid. The majority of the carotenoid contained in carrots is $\beta$-carotene, in range of $46.0-130.0 \mu \mathrm{g} / \mathrm{g}^{[1]}$. As an important source of vitamin A in the human diet, carotenoid has antioxidant and free-radical scavenging properties to reduce the risk of cancer, cardiovascular diseases and various types of

\section{Received date: 2016-01-21 Accepted date: 2017-03-12}

Biographies: Sun Xiaofei, $\mathrm{PhD}$ candidate, research interests: agricultural product processing technology, Email: sunxiaofei@, haust.edu.cn; Li Xinling, Experimentalist, research interests: food biochemistry, Email: lixinlingwjj@163.com; Fan Jinling, PhD, Professor, research interests: chemistry of natural product, Email: fanjinling@haust.edu.cn.

* Corresponding author: Zhu Wenxue, PhD, Professor, research interests: agricultural product processing technology. College of Food and Bioengineering, Henan University of Science and Technology, No.263, Kaiyuan Road, Luoyang 471023, Henan Province, China. Tel: +86-379-64282342; Email: zwx@mail. haust.edu.cn. degenerative chronic diseases ${ }^{[2-4]}$. Carrots have been wildly planted with high yield in China. However, fresh carrots are hard to be stored due to high moisture content. Dehydration is a feasible method, which may significantly extend the shelf life of dried carrots and still retain their nutrition and taste. Dehydrated carrots are also easier to transport and store ${ }^{[5]}$.

Healthy processed food requires not only good sensory properties but also retention of nutrients during processing. Carotene from carrots is in the form of crystal and is stored in the thylakoid membrane of chromoplast. Carotene is in conjunction with membrane proteins. Due to the structural integrity of cells and the protective effect of lipoproteins and other substances, the $\beta$-carotene exhibits high stability. During the dehydration process, the cell wall, cell membrane and thylakoid membrane of carrots are disrupted. The carotene partially dissolved in the lipids of cells has high sensitivity to light, heat and oxygen. Such a drying process causes a significant loss of $\beta$-carotene, color 
deterioration, and the decline of nutritional value ${ }^{[6]}$. Therefore, it is critical to select a suitable drying method in order to maintain the nutritional value of dried carrot products.

Hot air drying is the widely used for the dried vegetable production. However, there are many disadvantages such as slow process, high cost, poor rehydration performance and low product quality for final products $^{[7]}$. In addition, the highest thermal efficiency rate is only around $35 \%$ for this method ${ }^{[8]}$. During the dehydration process of carrots, the degradation of $\beta$-carotene may result in poor color and appearance. Thus, it is difficult to guarantee the product quality and nutrition. The research conducted by Hiranvarachat et al. ${ }^{[9]}$ showed that the hot air drying method under drying temperature of $60-80^{\circ} \mathrm{C}$ retained $58 \%-62 \%$ of the $\beta$-carotene. In the study presented, an obviously economical way of heat pump drying with low temperature was used to improve the retention rate of $\beta$-carotene in dried carrot products. The heat pump drying method dehydrates the vegetables by providing heat to a closed circulation of dry media such as air or other gases. The vegetables can be dehydrated when the media is heated. The advantages of heat pump include a higher thermal efficiency, a lower operating cost and a lower drying temperature. And this method is not affected by outside weather, keeping a stable temperature at any time of a year and producing no pollution to the environment. This method is particularly suitable for the vegetables dried with heat sensitive such as carrots which contain a high level of nutrition and moisture ${ }^{[10,11]}$.

The change of the nutritional value of carrot after drying is not only reflected in the retention rate of $\beta$-carotene, but also in the bioavailability. The absorption process of $\beta$-carotene in human body is divided into four steps: (1) releasing from the food matrix, (2) incorporating into mixed micelles in small intestine, absorption by small intestinal cells, (3) transporting to the lymphatic system, (4) transforming to vitamin A or stored in liver ${ }^{[12]}$. In this study, in vitro digestion experiment was used to evaluate the bioaccessibility of $\beta$-carotene which indicated the degree of releasing $\beta$-carotene from the food matrix to the gastrointestinal tract and incorporating into mixed micelles ${ }^{[13]}$.

Factors characterizing the bioaccessibility of $\beta$-carotene include matrix structure, lipid type, total intake of fiber, heat from food processing and homogenization ${ }^{[14]}$. As a heated process, the heat pump drying method may cause the changes in bioaccessibility of $\beta$-carotene in carrots, which may affect its bioavailability to the human body.

In vitro digestion model was considered as a suitable method for studying bioaccessibility of carotenoid from different food matrix. The main advantage of such model was the possibility to screen for factors which might affect the carotenoid bioaccessibility in an economical manner ${ }^{[15]}$. In vitro carotenoid bioaccessibility was described as the fraction of carotenoid transferred from the food matrix to the micellar phase obtained by microfiltration ${ }^{[16]}$ and to the supernatant obtained by low-speed centrifugation ${ }^{[17]}$. For vegetables and fruits, in vitro digestion method was recommended to evaluate the in vivo bioavailability of carotenoids $^{[18]}$.

Although existing studies demonstrated various drying methods and the impact on the loss of carotenoids under different technology parameters, little information was published for the bioaccessibility and bioavailability. In this study, we used in vitro digestion model to demonstrate the effect of heat pump drying on the bioaccessibility of $\beta$-carotene in carrots at different drying temperatures. In addition, it was believed that fat can improve its absorption and utilization ${ }^{[19,20]}$, because $\beta$-carotene is a fat-soluble nutrient. However, other studies reported that fat had no significant effect on the $\beta$-carotene bioaccessibility ${ }^{[21,22]}$. Due to the contradicting conclusions from these studies, it was necessary to study the impact of dietary fat on $\beta$-carotene bioaccessibility in heat pump dried carrots.

\section{Materials and methods}

\subsection{Chemicals and standards}

Porcine pepsin, porcine pancreatin and porcine bile extract were purchased from Sigma-Aldrich Chemical Company (St Louis, MO, USA). HPLC-grade methanol and ethyl acetate were purchased from Xilong Chemical 
Co., Ltd. (Shanghai, China). Standard $\beta$-carotene was purchased from Sigma-Aldrich Chemical Company (St Louis, MO, USA). For the preparation of the aqueous phase, deionized water, purified by a Milli-Q Organex system was used. Other chemicals used were all in analytical grade.

\subsection{Preparation of samples}

Fresh carrots were obtained from a local grocery store in Luoyang, China. They were washed with distilled water, peeled and chopped to approximately $1 \mathrm{~mm} \times$ $1 \mathrm{~mm} \times 1 \mathrm{~mm}$ in dimensions, which are similar to the shape and size after chewing. They were then divided into groups of $10 \mathrm{~g}$ each and dried with a heat pump. The heat pump temperatures were set at $40^{\circ} \mathrm{C}, 50^{\circ} \mathrm{C}$ and $60^{\circ} \mathrm{C}$ with the same wind speed at $1.0 \mathrm{~m} / \mathrm{s}$. After the drying temperatures and wind speed were stable, the samples were put into material plates for dehydration. Samples' weights were monitored frequently until the moisture content reduced to $10 \%$. Then, the samples were put into $95^{\circ} \mathrm{C}$ deionized water and rehydrate for 2 min. Finally, the surface water was wiped for further use.

In order to study the effect of dietary fat on $\beta$-carotene bioaccessibility of heat pump dried carrots, $2.5 \%, 5 \%$ and $10 \%(\mathrm{w} / \mathrm{w})$ sunflower oil were added to some of the samples during in vitro digestion. The amount of oil added was within the range of normal diet (below $10 \%)^{[23]}$. Also, the sunflower oil was purchased from local grocery store and has been reported not to contain any $\beta$-carotene ${ }^{[24]}$. The tests were repeated three times for accuracy.

\subsection{In vitro digestion}

The in vitro digestion procedure was carried out according to previous studies ${ }^{[16,17]}$ with minor modifications such as oral digestion was added. All solutions for the in vitro digestion were prepared right before the test was performed.

Ten gram of fresh carrots or the equivalent amounts of samples treated with different drying temperatures were transferred to an amber glass flask. Five milliliter of an artificial saliva solution $(50 \mathrm{mM} \mathrm{NaCl}, 10 \mathrm{mM}$ $\mathrm{KH}_{2} \mathrm{PO}_{4}, 2 \mathrm{mM} \mathrm{CaCl}, 40 \mathrm{mM} \mathrm{NaHCO} 3$ ) were then added to the samples, and the $\mathrm{pH}$ was adjusted to 6.7 by using $1 \mathrm{M} \mathrm{NaOH}$. Subsequently, $100 \mu \mathrm{L}$ of a fresh $\alpha$-amylase solution which containing $25 \mathrm{U}$, as well as another $5 \mathrm{~mL}$ of artificial saliva solution were added to start oral digestion stage. In order to achieve sample homogeneity, the samples were shaken at $95 \mathrm{r} / \mathrm{min}$ for $1 \mathrm{~min}$ in a shaking incubator at $37^{\circ} \mathrm{C}$. For mimicking the gastric phase, $1 \mathrm{M} \mathrm{HCl}$ was added to adjust the $\mathrm{pH}$ to 2.0. Then, $5 \mathrm{~mL}$ pre-heated $\left(37^{\circ} \mathrm{C}\right)$ gastric electrolyte solution $\left(51 \mathrm{mM} \mathrm{NaCl}, 14.8 \mathrm{mM} \mathrm{KCl}, 3.7 \mathrm{mM} \mathrm{KH}{ }_{2} \mathrm{PO}_{4}\right.$, $10 \mathrm{mM} \mathrm{CaCl}_{2} \cdot 2 \mathrm{H}_{2} \mathrm{O}$ and $3.4 \mathrm{mM} \mathrm{MgCl} 2 \cdot 6 \mathrm{H}_{2} \mathrm{O}$ ) were also added. Finally, $2 \mathrm{~mL}$ porcine pepsin $(40 \mathrm{mg} / \mathrm{mL}$, pepsin dissolved in $0.1 \mathrm{M} \mathrm{HCl}$ ) were added to the flask, and it was then flushed with nitrogen, sealed and rested in a constant temperature shaking incubator at $37^{\circ} \mathrm{C}$ and $95 \mathrm{r} / \mathrm{min}$ for $1 \mathrm{~h}$. Subsequently, $0.9 \mathrm{M} \mathrm{NaHCO}_{3}$ solution was added to adjust the $\mathrm{pH}$ to 5.3. Then, $9 \mathrm{~mL}$ of a porcine bile extract/pancreatin solution $(12 \mathrm{mg} / \mathrm{mL}$ porcine bile extract, $2 \mathrm{mg} / \mathrm{mL}$ pancreatin in $0.1 \mathrm{M}$ $\mathrm{NaHCO}_{3}$ ) were added and the $\mathrm{pH}$ was then adjusted to 7.5 by using $1 \mathrm{M} \mathrm{NaOH}$. In order to complete the gastrointestinal digestion, the flask was again flushed with nitrogen and was incubated for $2 \mathrm{~h}$ at $37^{\circ} \mathrm{C}$ and $95 \mathrm{r} / \mathrm{min}$ in the shaking incubator. After the completion of digestion, the samples were centrifuged at $5000 \mathrm{~g}$ for 20 min to obtain the supernatant fraction which was used for analyzing the extent of the release of $\beta$-carotene (release rate). The supernatant fraction was then microfiltered with $0.22 \mu \mathrm{m}$ pore size membrane to get the micellar fraction which was then used for analyzing the degree that $\beta$-carotene may be absorbed by intestine (micellar rate). All procedures were performed under dimmed light and repeated three times for accuracy.

\subsection{Extraction of $\boldsymbol{\beta}$-carotene from carrot samples}

$\beta$-carotene extracted from carrot samples were based on previous studies ${ }^{[25]}$. Weighed $1 \mathrm{~g}$ fresh carrot sample or $0.1 \mathrm{~g}$ dried carrot sample and placed it in a mortar. Added a small amount of quartz sand into the mortar. Then, ground and extracted the sample with the extracting agent (hexane/ethanol/acetone: 50:25:25, v/v/v) which contains $0.1 \%(\mathrm{w} / \mathrm{v})$ butylated hydroxytoluene (BHT) for several times until the extraction agent and the carrots residue were colorless. Subsequently, combined all resulting extract in a new test tube, and added $15 \mathrm{~mL}$ 
of distilled water as well as $1 \mathrm{~g}$ of $\mathrm{CaCl}_{2} \cdot 2 \mathrm{H}_{2} \mathrm{O}$. Shaking the test tube and rested until stratification. The upper organic phase after stratification was taken for further testing. All extractions and analyses of samples were protected from light.

\subsection{Extraction of $\beta$-carotene from in vitro digested samples}

Extracting agent (hexane/ethanol/acetone: 50:25:25, $\mathrm{v} / \mathrm{v} / \mathrm{v})$ containing $0.1 \%(\mathrm{w} / \mathrm{v})$ BHT need be used to extract the $\beta$-carotene in the supernatant and in the micellar fraction which was obtained from the prior step of the in vitro digestion. It was extracted twice with equal volumes. The extracts were shaken gently and waited for stratification in a dark room. Subsequently, organic fractions were combined into a test tube and dehydrated by nitrogen at $35^{\circ} \mathrm{C}$. Finally, the residue was dissolved in mobile phase (methanol/ethyl acetate: 90:10, v/v).

\section{$2.6 \beta$-carotene analysis by HPLC}

Reversed phase HPLC (Agilent 1260 Infinity, Agilent Technologies, America) was used for analyzing $\beta$-carotene. The absorption spectra for DAD detector was ranged between $190 \mathrm{~nm}$ and $700 \mathrm{~nm}$, and detection of $\beta$-carotene was carried out at $450 \mathrm{~nm}$. Separations of $\beta$-carotene were carried out by using ZORBAX SB-C18 column ( $5 \mu \mathrm{m}, 250 \times 4.6 \mathrm{~mm}$, Agilent). The injection volume was $10 \mu \mathrm{L}$. Analysis used different proportions of methanol (A) and ethyl acetate (B) with a flow rate of $1.2 \mathrm{~mL} / \mathrm{min}$ to elute $\beta$-carotene from the column. The solvent gradient was as follows: $0-15 \mathrm{~min}, 90 \%-85 \% \mathrm{~A}$; $15-30 \mathrm{~min}, 85 \%-70 \%$ A. $\beta$-carotene is quantified by using standard curves, and the curves were constructed by eight concentration points with a concentration range from 0 to $100 \mu \mathrm{g} / \mathrm{mL}$.

\subsection{Light microscopy}

To observe the carotenoid morphology of samples, Nikon ECLIPSE TS100-F (Japan) inverted bright field light microscope was used. For the fresh carrot samples, a section of the sample was cut as thin as possible directly using a razor blade and observe on a slide. For the heat pump dried carrots samples, the samples rehydrated in normal saline at room temperature for $15 \mathrm{~min}$. Then, took the sample out and drain the surface. Subsequently, cut a section of the sample and observe on a slide the same way as mentioned above for the fresh carrots sample.

\subsection{Calculation methods and statistical analysis}

The $\beta$-carotene retention rate of dried carrots refers to the percentage of $\beta$-carotene retained after dehydration as compared to its initial content in the fresh carrots. Bioaccessibility of $\beta$-carotene is measured by the percentage of $\beta$-carotene transferred from the food matrix to the supernatant and the micellar phase. It can be calculated based on the following Equations (1) and (2):

$$
\begin{aligned}
& n_{1}-\beta=\frac{m_{1}}{m_{3}} \times 100 \% \\
& n_{2}-\beta=\frac{m_{2}}{m_{3}} \times 100 \%
\end{aligned}
$$

where, $m_{1}$ is the mass ratio of $\beta$-carotene in the supernatant, $\mu \mathrm{g} / \mathrm{g} ; m_{2}$ is the mass ratio of $\beta$-carotene in micellar phase, $\mu \mathrm{g} / \mathrm{g} ; m_{3}$ is the mass ratio of $\beta$-carotene in carrot sample, $\mu \mathrm{g} / \mathrm{g} ; n_{1}-\beta$ is carotene release rate, $\% ; n_{2}-\beta$ is carotene micellar rate, $\%$.

Statistical analysis used SPSS software (Version 18.0). The data was recorded and presented as mean \pm SD. By using Tukey's post hoc test, the mean variances were analyzed and significant differences between groups were determined. Differences were considered to be significant at $p<0.05$.

\section{Results and discussion}

\section{1 $\beta$-carotene retention rate of carrots under different heat pump drying temperatures}

Although the drying process reduced the moisture content of carrots, making them easy to store and transport, it also inevitably caused the degradation of $\beta$-carotene. All-trans- $\beta$-carotene existed naturally in carrots. Due to the existence of a large number of unsaturated structure, the all-trans- $\beta$-carotene is very active in nature. It was easily degraded and formed isomers at a high drying temperature ${ }^{[26]}$. Therefore, in this study, low-temperature heat pump drying method was used to avoid the degradation of $\beta$-carotene in carrots. This method improved the $\beta$-carotene retention rate and maintained the nutritional value of the dried products.

From Figure 1, the drying temperature caused the loss of $\beta$-carotene in carrots during the dehydration process. 
$\beta$-carotene retention rate changed with different drying temperature. When the drying temperature was $60^{\circ} \mathrm{C}$, the $\beta$-carotene retention rate was $73.0 \%$. By reducing the drying temperature to $50^{\circ} \mathrm{C}, \beta$-carotene retention rate increased to $77.9 \%$. By further reducing the drying temperature to $40^{\circ} \mathrm{C}$, the $\beta$-carotene retention rate increased to $81.8 \%$. This indicated that the retention of $\beta$-carotene was largely dependent on the drying temperature. The retention rate was significantly raised as the drying temperature decreased $(p<0.05)$. In the study conducted by Hiranvarachat et al. ${ }^{[9]}$, the $\beta$-carotene retention rate of carrots was $58 \%-62 \%$ with hot air drying at $60^{\circ} \mathrm{C}-80^{\circ} \mathrm{C}$ and $69 \%-74 \%$ with vacuum drying. The heat pump drying method used in this study, in comparison, made $\beta$-carotene retention rate close to the level of the vacuum drying and was significantly higher than that of the previous hot air drying method.

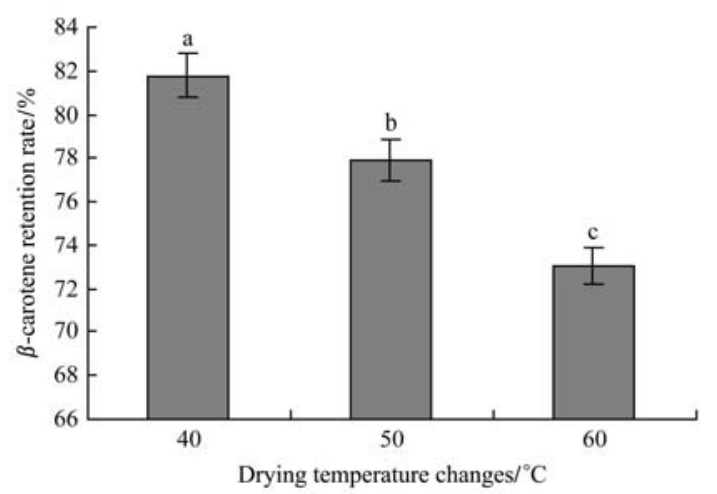

Note: Different letters (a, b and c) indicate significant differences $(p<0.05)$.

Figure $1 \beta$-carotene retention rates of carrots under different heat pump drying temperatures $(n=3)$

\subsection{Impact of the heat pump drying temperature on} bioaccessibility of $\boldsymbol{\beta}$-carotene in carrots

For the nutritional value of a food, the most important thing is whether the nutrients can be efficiently absorbed and play a role in maintaining health. Thus, the bioaccessibility of a nutrient is much more important than its total content.

After in vitro digestion of the samples, low-speed centrifugation was used to obtain the supernatant, which was used to analyze the extent of $\beta$-carotene released from the food matrix (release rate). In order to be absorbed by the small intestine, $\beta$-carotene must be incorporated into the micelles formed by bile salts, phospholipids and lipid hydrolysates after releasing from the food matrix ${ }^{[15]}$. Therefore, $0.22 \mu \mathrm{m}$ membrane was selected in this study to filter the supernatant to obtain the micellar phase. The micellar rate of the $\beta$-carotene was then determined to represent the bioaccessibility.

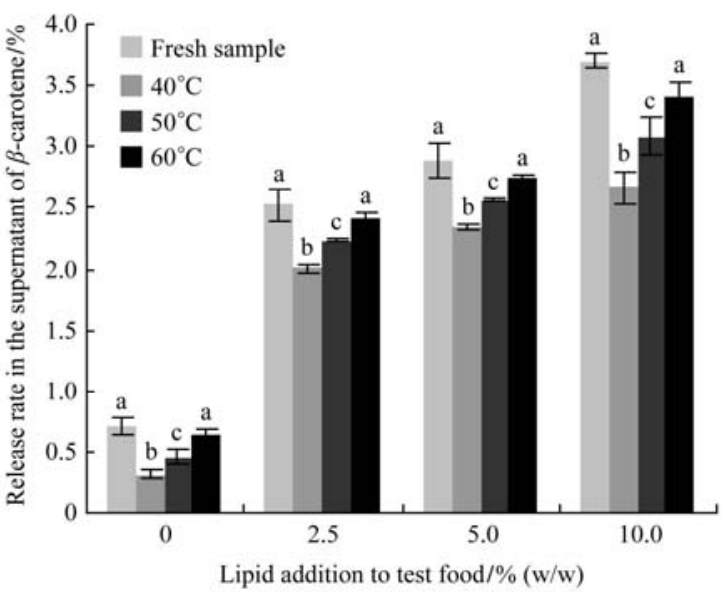

Note: Different letters ( $\mathrm{a}, \mathrm{b}$ and $\mathrm{c})$ indicate significant differences $(p<0.05)$.

Figure $2 \beta$-carotene release rates of carrots under different heat pump drying temperatures $(n=3)$

Figure 2 showed the release rate of $\beta$-carotene in fresh carrot or in the samples obtained after drying at different temperatures using heat pump when different amounts of fat were added during digestion. When the same amount of fat was added to the samples, the $\beta$-carotene release rate from the fresh carrot sample was significantly higher than that of the carrot samples dried at $40^{\circ} \mathrm{C}$ and $50^{\circ} \mathrm{C}$. However, the difference of $\beta$-carotene release rate was not significant between the fresh carrot sample and that dried at $60^{\circ} \mathrm{C}(p<0.05)$. For the dried samples, $\beta$-carotene release rate increased significantly when the drying temperature was raised from $40^{\circ} \mathrm{C}$ to $60^{\circ} \mathrm{C}$ $(p<0.05)$. This study showed that the fresh carrot sample had the highest release rate of $\beta$-carotene. Interestingly, the micelles rate of $\beta$-carotene in carrot, which indicated the impact on bioaccessibility, was higher in the dried than the fresh samples, opposite to the trend seen in the release rate. As shown in Figure 3, when the same amount of oil was added to the samples, the bioaccessibility of the $\beta$-carotene in dried samples was significantly higher than that in the fresh carrot sample. Particularly, the highest $\beta$-carotene bioaccessibility was from the sample dried at the temperature of $60^{\circ} \mathrm{C}$, followed by that of $50^{\circ} \mathrm{C}$ and $40^{\circ} \mathrm{C}$. The observed differences were significant $(p<0.05)$. It indicated that fresh carrots had the lowest $\beta$-carotene micellar rate. Figures 2 and 3 showed that the 
$\beta$-carotene release rate and micellar rate were improved in both the fresh and dried carrots when more oil was added in the digestion process. However, the overall trend and statistically significant difference of each sample did not change compared with no oil added.

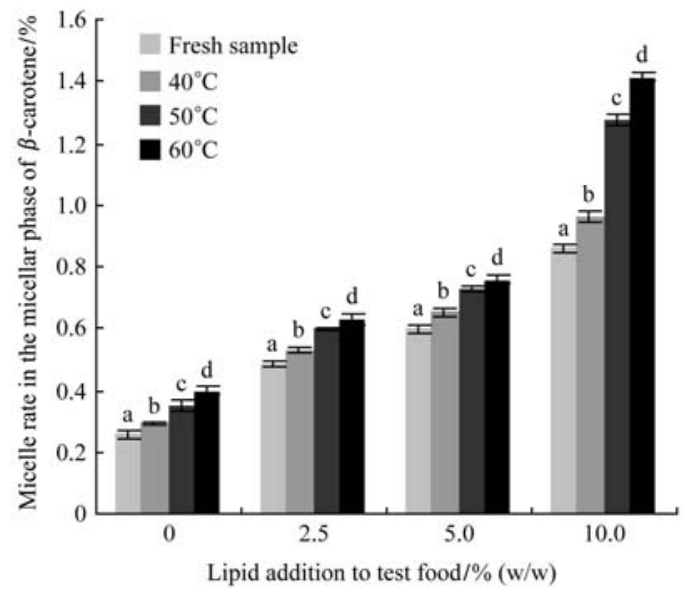

Note: Different letters (a, b, c and d) indicate significant differences $(p<0.05)$.

Figure $3 \beta$-carotene micellar rates of carrots under different heat pump drying temperatures $(n=3)$

The reason for the change of the release rate and micellar rate may be due to the structural changes of the carrots after drying. Sample surface water vaporized during drying. The diffusion of moisture within carrot caused the contraction of the tissue cells in samples. This change hid the release of $\beta$-carotene from the cell to the digestive juice, which results in the lower release rate after drying than the fresh samples in most cases. The study described by Tydeman et al. showed that during the digestion process, digestive juice only made the cell wall of the digested carrot slightly swollen. Most cells remained intact after digestion which impeded the release of $\beta$-carotene to the digestive juices ${ }^{[27,28]}$. However, in this study, the micellar rate was higher at $60^{\circ} \mathrm{C}$ than that in the other samples. It was speculated that the morphology of carotenoid at different drying temperatures, which deposits in the chromoplasts of carrot cells, has a more significant impact on the release of $\beta$-carotene from the matrix to the supernatant/micellar fraction. Schweiggert et al. ${ }^{[29]}$ reported in the chromoplasts of mango and papaya, the physical presence of carotenoids were in a liquid crystalline and/or lipid dissolved form, while carrot and tomato contained carotenoids in solid crystalline physical states. The $\beta$-carotene bioaccessibility of the liquid crystalline form is higher than that of the solid crystalline form ${ }^{[29]}$. It can be seen from Figure 4 that the carotenoids of fresh carrots sample were in the form of needle-shaped solid crystal in the chromoplasts of the carrot's cells. During dehydration process, the carotenoids in the chromoplasts of the carrot's cells received heat and transformed from the solid crystalline form to the liquid crystalline form gradually with the increase of drying temperature. This transformation made $\beta$-carotene more easily to be incorporated into micellar phase and improved its bioaccessibility. When the temperature was raised from $40^{\circ} \mathrm{C}$ to $60^{\circ} \mathrm{C}$, less needle-shaped carotenoids solid crystal was observed in the cells of dried carrot samples, indicating more carotenoids was present in the liquid crystalline form. These observations explained the significant difference in the bioaccessibility of $\beta$-carotene under different drying temperatures. Although the $\beta$-carotene release rate in fresh carrot samples was the highest, the $\beta$-carotene was still in solid crystalline form due to a lack of heat treatment, resulting in the lowest micellar rate.

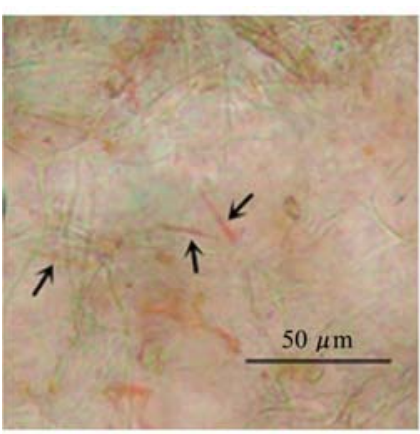

a. Fresh carrot

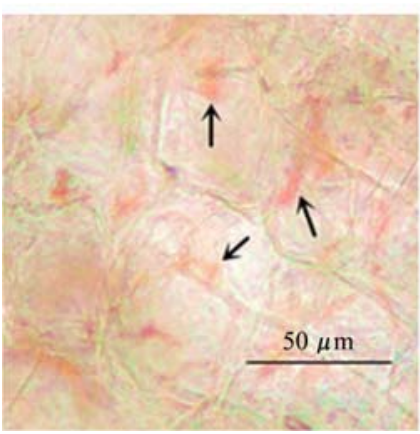

c. $50^{\circ} \mathrm{C}$

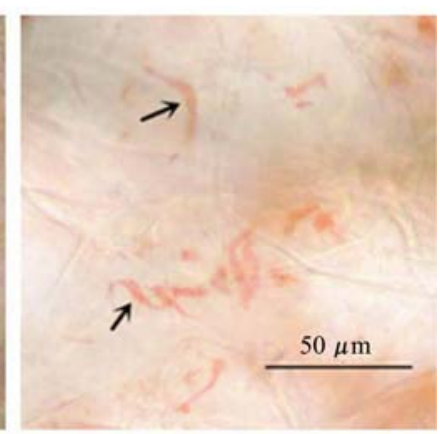

b. $40^{\circ} \mathrm{C}$

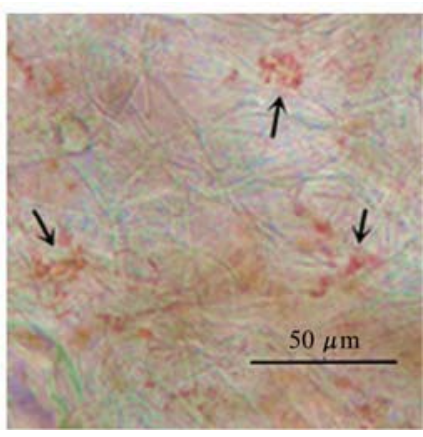

d. $60^{\circ} \mathrm{C}$
Figure 4 Light micrographs of carrot samples with the treatment of different heat pump drying temperatures and samples without heat pump drying process (Arrows mark carotenoids).

\subsection{Impact of oil on $\boldsymbol{\beta}$-carotene bioaccessibility}

The previous studies reported different effects of oil on the bioaccessibility of $\beta$-carotene. The research from 
Ornelas-Paz et al. ${ }^{[19]}$, added chicken into mangoes at different stages of maturation (slightly ripe, moderately ripe and fully ripe). The micellar rate of $\beta$-carotene increased by $25.7 \%, 114.4 \%$ and $231.1 \%$, respectively ${ }^{[19]}$. Hornero-Mendez et al. ${ }^{[20]}$ added fat into carrot pomace which caused the micellar rate of $\beta$-carotene to increase along with the amount of fat added. However, Knockaert et al. ${ }^{[21]}$ indicated that prior to a high-pressure homogenization of carrot puree, added fat had no significant effect on the release rate of $\beta$-carotene. Fleshman et al. ${ }^{[22]}$ research also showed there was no significant effect on melon's $\beta$-carotene micellar rate when adding $2.5 \%$ to $3 \%$ fat. Therefore, in order to study the effect of oil on the transfer of $\beta$-carotene from the matrix to the supernatant and micelles in heat pump dried carrots, fresh and dried carrot samples were digested when $2.5 \%$ to $10 \%(\mathrm{w} / \mathrm{w})$ sunflower oil was added.

It can be seen from Figures 5 and 6 that with increased amount of oil the $\beta$-carotene release rate and the micellar rate significantly increased in all fresh and dried carrot samples, and the release rate was significantly correlated with the micellar rate $(r=0.792$, $p<0.01)$. The significant difference observed $(p<0.05)$ indicated that under the same drying conditions and treatments, the release rate and micellar rate of $\beta$-carotene with $10 \%$ oil added were significantly higher than that of the ones with $2.5 \%$ and $5 \%$ oil added. Also, the release rate and micellar rate of $\beta$-carotene with $2.5 \%$ and $5 \%$ oil added were significantly higher than that of the blank sample (no oil). Finally, there were significant differences between the samples with $2.5 \%$ and $5 \%$ oil added. This result clearly showed that oil was necessary for the improvement of the bioaccessibility of $\beta$-carotene.

Carotenoid is a fat-soluble nutrient. It is widely approved that dietary fat helps the absorption of $\beta$-carotene by intestinal cells. Fat supply a hydrophobic domain within which the carotenoids can be solubilized during the digestion process and promotes the carotenoids transferring to lipid particles ${ }^{[30]}$. Furthermore, dietary fat can promote the secretion of bile salts and pancreatic lipase in a human body which is conductive to the formation of lipid micelles ${ }^{[30]}$. This also improves the absorption of $\beta$-carotene by intestinal cells.

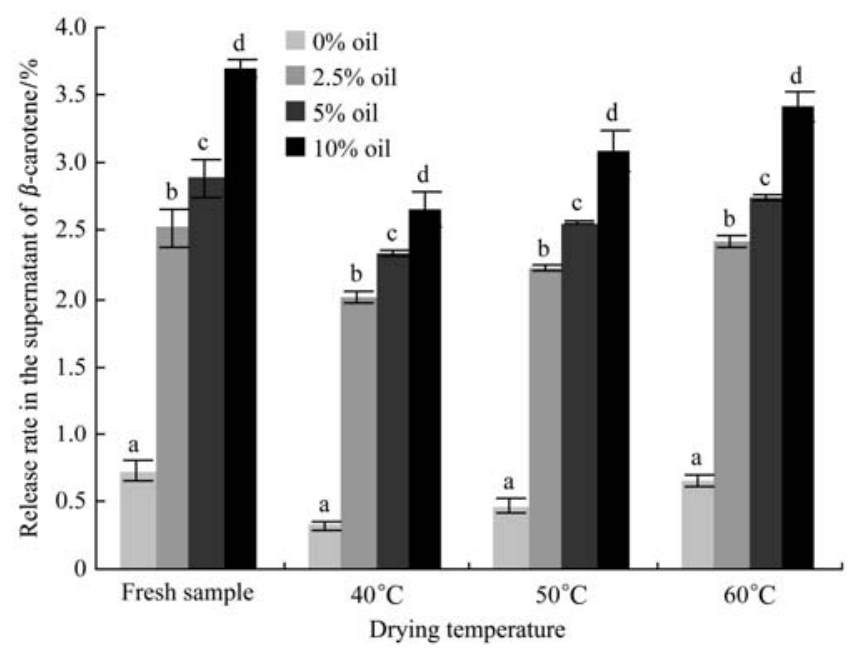

Note: Different letters (a, b, c and d) indicate significant differences $(p<0.05)$. Figure $5 \beta$-carotene release rates of carrots with different amount of oil added $(n=3)$

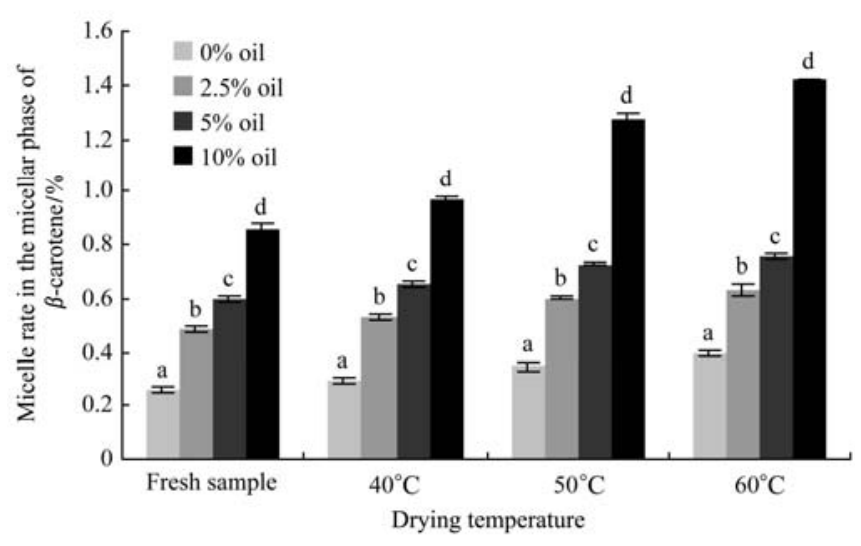

Note: Different letters (a, b, c and d) indicate significant differences $(p<0.05)$

Figure $6 \quad \beta$-carotene micellar rates of carrots with different amount of oil added $(n=3)$

\section{Conclusions}

The temperature of the heat pump drying process and an amount of oil added showed significant impact on the $\beta$-carotene bioaccessibility in carrots. After carrots are dried, carotenoids in the chromoplasts transformed from a solid crystalline into a liquid-crystalline form. The change in the physical form of carotenoid could be the reason for the significantly higher $\beta$-carotene bioaccessibility in dried carrots than that in fresh carrots. Furthermore, the study revealed the importance of adding oil to improve the bioaccessibility of $\beta$-carotene.

\section{Acknowledgements}

Thanks to National Natural Science Funds of China (No.31171723) for the support of this study. 


\section{[References]}

[1] Zaccari F, Cabrera M C, Ramos A, Saadoun A. In vitro bioaccessibility of $\beta$-carotene, $\mathrm{Ca}, \mathrm{Mg}$ and $\mathrm{Zn}$ in landrace carrots (Daucus carota, L.). Food Chemistry, 2015; 166: 365-371.

[2] Gregori N Z, Goldhardt R. Nutritional supplements for age-related macular degeneration. Current Ophthalmology Reports, 2015; 3(1): 34-39.

[3] Fiedor J, Burda K. Potential role of carotenoids as antioxidants in human health and disease. Nutrients, 2014; 6(2): 466-488.

[4] Bacchetti T, Tullii D, Masciangelo S, Gesuita R, Skrami E, Bruge F, et al. Effect of a barley-vegetable soup on plasma carotenoids and biomarkers of cardiovascular disease. Journal of Clinical Biochemistry \& Nutrition, 2015; 57(1): 66-73.

[5] Cárdenas-Bailón F, Osorio-Revilla G, Gallardo-Velázquez T. Evaluation of quality parameters of dried carrot cubes in a spout-fluidized-bed dryer with and without draft tube. Journal of Food Measurement \& Characterization, 2016; $1-11$.

[6] Demiray E, Tulek Y. Degradation kinetics of $\beta$-Carotene in carrot slices during convective drying. International Journal of Food Properties, 2017; 20(1): 151-156.

[7] Luo D L, Liu J, Liu Y H, Ren G Y. Drying characteristics and mathematical model of ultrasound assisted hot-air drying of carrots. Int J Agric \& Biol Eng, 2015; 8(4): 124-132.

[8] Hande A R, Swami S B, Thakor N J. Effect of drying methods and packaging materials on quality parameters of stored kokum rind. Int J Agric \& Biol Eng, 2014; 7(4): 114-126.

[9] Hiranvarachat B, Suvarnakuta P, Devahastin S. Isomerisation kinetics and antioxidant activities of $\beta$-carotene in carrots undergoing different drying techniques and conditions. Food Chemistry, 2008; 107(4): 1538-1546.

[10] Gungor A, Tsatsaronis G, Gunerhan H, Hepbasli A. Advanced exergoeconomic analysis of a gas engine heat pump (GEHP) for food drying processes. Energy Conversion \& Management, 2015; 91:132-139.

[11] Colak N, Hepbasli A. A review of heat-pump drying (HPD): Part 2-Applications and performance assessments. Energy Conversion and Management, 2009; 50(9): 2187-2199.

[12] Thakkar S K, Maziya-Dixon B, Dixon A G O, Failla M. $\beta$-Carotene micellarization during in vitro digestion and uptake by Caco- 2 cells is directly proportional to $\beta$-carotene content in different genotypes of cassava. The Journal of Nutrition, 2007; 13(10): 2229-2233.

[13] Pugliese A, O'Callaghan Y, Tundis R, Galvin K, Menichini F, O'Brien $\mathrm{N}$, et al. In vitro investigation of the bioaccessibility of carotenoids from raw, frozen and boiled red chili peppers (Capsicum annuum). European Journal of Nutrition, 2014; 53(2): 501-510.

[14] Lemmens L, Colle I, Buggenhout S V, Palmero P, Loey A V, Hendrickx M. Carotenoid bioaccessibility in fruit- and vegetable-based food products as affected by product (micro) structural characteristics and the presence of lipids: A review. Trends in Food Science \& Technology, 2014; 38(2): $125-135$.

[15] Anton B, Marie L A, Ulf S. In vitro bioaccessibility of $\beta$-carotene from heat-processed orange-fleshed sweet potato. Journal of Agricultural and Food Chemistry, 2009; 57: 9693-9698.

[16] Veda S, Kamath A, Platel K, Begum K, Srinivasan K. Determination of bioaccessibility of $\beta$-carotene in vegetables by in vitro methods. Molecular Nutrition and Food Research, 2006; 50(11): 1047-1052.

[17] Granado-Lorencio F, Olmedilla-Alonso B, Herrero-Barbudo C, Blanco-Navarro I, Perez-Sacristan B, Blazquez-Garcia S. In vitro bioaccessibility of carotenoids and tocopherols from fruits and vegetables. Food Chemistry, 2007; 102(3): 641-648.

[18] Granado F, Olmedilla B, Herrero C, Perez-Sacristan B, Blanco I, Blazquez S. Bioavailability of carotenoids and tocopherols from broccoli: in vivo and in vitro assessment. Exp Biol Med, 2006; 231(11): 1733-1738.

[19] Ornelas-Paz J D J, Failla M L, Yahia E M, Alfonso G B. Impact of the stage of ripening and dietary fat on in vitro bioaccessibility of $\beta$-carotene in "Ataulfo" mango. Journal of Agricultural and Food Chemistry, 2008; 56(4): 1511-1516.

[20] Hornero-Mendez D, Minguez-Mosquera M I. Bioaccessibility of carotenes from carrots: effect of cooking and addition of oil. Innovative Food Science \& Emerging Technologies, 2007; 8(3): 407-412.

[21] Knockaert G, Lemmens L, Buggenhout S V, Hendrickx M, Loey A V. Changes in $\beta$-carotene bioaccessibility and concentration during processing of carrot puree. Food Chemistry, 2012; 133(1): 60-67.

[22] Fleshman M K, Lester G E, Riedl K M, Kopec R E, Narayanasamy S, Curley R W, et al. Carotene and novel apocarotenoid concentrations in orange-fleshed Cucumis melo melons: determinations of $\beta$-carotene bioaccessibility and bioavailability. Journal of Agricultural and Food Chemistry, 2011; 59(9): 4448-4454.

[23] Tennant D, Gosling J P. Modelling consumer intakes of vegetable oils and fats. Food Additives \& Contaminants Part A Chemistry Analysis Control Exposure \& Risk Assessment, 2015; 32(9): 1397-1405.

[24] Slavova-Kazakova A, Karamać M, Kancheva V, Amarowicz R. Antioxidant activity of flaxseed extracts in lipid systems. Molecules, 2016; 21(1): 17-20.

[25] Bengtsson A, Namutebi A, Alminger M L, Svanberg U. 
Effects of various traditional processing methods on the all-trans- $\beta$-carotene content of orange-fleshed sweet potato. Journal of Food Composition and Analysis, 2008; 21: 134-143.

[26] Demiray E, Tulek Y. Degradation kinetics of $\beta$-carotene in carrot slices during convective drying. International Journal of Food Properties, 2017; 20(1): 151-156.

[27] Tydeman E A, Parker M L, Wickham M S, Rich G T, Faulks R M, Gidley M J, et al. Effect of carrot (Daucus carota) microstructure on carotene bioaccessibilty in the upper gastrointestinal tract.1. In vitro simulations of carrot digestion. Journal of Agricultural and Food Chemistry, 2010; 58(17): 9847-9854.
[28] Tydeman E A, Parker M L, Faulks R M, Cross K L, Fillery-Travis A, Gidley M J, et al. Effect of carrot (Daucus carota) microstructure on carotene bioaccessibility in the upper gastrointestinal tract.2. In vivo digestions. Journal of Agricultural and Food Chemistry, 2010; 58(17): 9855-9860.

[29] Schweiggert R F, Mezger D, Schimof F, Steingass C B, Carle R. Influence of chromoplast morphology on carotenoid bioaccessibility of carrot, mango, papaya, and tomato. Food Chemistry, 2012; 135: 2736-2742.

[30] Borel P. Factors affecting intestinal absorption of highly lipophilic food microconstituents (fat-soluble vitamins, carotenoids and phytosterols). Clin Chem Lab Med, 2003; 41(8): 979-994. 